\title{
Stable carbon isotope fractionation in chlorinated ethene degradation by bacteria expressing three toluene oxygenases
}

\author{
Scott R. Clingenpeel ${ }^{1 \dagger}$, Jaina L. Moan ${ }^{2}$, Danielle M. McGrath ${ }^{1 \dagger}$, Bruce A. Hungate $^{1,2,3}$ and \\ Mary E. Watwood ${ }^{1 *}$
}

1 Department of Biological Sciences, Northern Arizona University, Flagstaff, AZ, USA

${ }^{2}$ Colorado Plateau Stable Isotope Laboratory, Northern Arizona University, Flagstaff, AZ, USA

${ }^{3}$ Merriam-Powell Center for Environmental Research, Northern Arizona University, Flagstaff, AZ, USA

\section{Edited by:}

Qiaoyun Huang, Huazhong

Agricultural University, China

Reviewed by:

Qiaoyun Huang, Huazhong

Agricultural University, China

Jeremy Semrau, University of

Michigan, USA

Yucheng Feng, Auburn University,

USA

*Correspondence:

Mary E. Watwood, Department of

Biological Sciences, Northern Arizona

University, P.O. Box 5640, Flagstaff,

AZ 86011, USA

e-mail: maribeth.watwood@nau.edu

${ }^{\dagger}$ Present address:

Scott R. Clingenpeel, DOE Joint

Genome Institute, Walnut Creek, CA,

USA.;

Danielle M. McGrath, MD Anderson

Cancer Center, The University of

Texas, Houston, TX, USA.
One difficulty in using bioremediation at a contaminated site is demonstrating that biodegradation is actually occurring in situ. The stable isotope composition of contaminants may help with this, since they can serve as an indicator of biological activity. To use this approach it is necessary to establish how a particular biodegradation pathway affects the isotopic composition of a contaminant. This study examined bacterial strains expressing three aerobic enzymes for their effect on the ${ }^{13} \mathrm{C} /{ }^{12} \mathrm{C}$ ratio when degrading both trichloroethene (TCE) and cis-1,2-dichloroethene (c-DCE): toluene 3-monoxygenase, toluene 4-monooxygenase, and toluene 2,3-dioxygenase. We found no significant differences in fractionation among the three enzymes for either compound. Aerobic degradation of c-DCE occurred with low fractionation producing $\delta^{13} \mathrm{C}$ enrichment factors of $-0.9 \pm 0.5$ to $-1.2 \pm 0.5$, in contrast to reported anaerobic degradation $\delta^{13} \mathrm{C}$ enrichment factors of -14.1 to $-20.4 \%$. Aerobic degradation of TCE resulted in $\delta^{13} \mathrm{C}$ enrichment factors of $-11.6 \pm 4.1$ to $-14.7 \pm 3.0 \%$ o which overlap reported $\delta^{13} \mathrm{C}$ enrichment factors for anaerobic TCE degradation of -2.5 to $-13.8 \%$. The data from this study suggest that stable isotopes could serve as a diagnostic for detecting aerobic biodegradation of TCE by toluene oxygenases at contaminated sites.

Keywords: stable carbon isotope, trichloroethene, cis-1,2-dichloroethene, toluene oxygenase, aerobic biodegradation

\section{INTRODUCTION}

Chlorinated ethenes are among the most ubiquitous groundwater contaminants in the industrialized world. These harmful chemicals not only threaten water supplies, but they can be difficult and costly to remove from subsurface environments. Because of this, many remediation operations have implemented bioremediation strategies that exploit the ability of several groups of microorganisms to degrade these contaminants. The assessment of biodegradation at contaminated field sites can be extremely challenging. For biodegradation of several important pollutants specific intermediates are known and allow at least a qualitative assessment of biodegradation as is the case with reductive dechlorination of chlorinated ethenes (Magar et al., 2001). The quantification of biodegradation is more difficult because of the need for conclusive mass balances which are often problematic due to insufficient knowledge about the groundwater flow, spatial and temporal heterogeneity, the limited number and placement of sampling wells, and insufficient observation times. Despite these difficulties, quantitative data are considered important for the protection of public welfare (National Research Council, 2000).

In planning and implementing biodegradation, it is essential to estimate the different sinks for organic contaminants such as dilution, sorption, or biodegradation, because the last of these is the only process that destroys the contaminant. This is especially important for monitored natural attenuation, which relies on natural biodegradation by indigenous microbial communities. Stable carbon isotopic analysis of dissolved organic contaminants has the potential not only to identify biotic and abiotic processes, but also to directly assess the extent of intrinsic biodegradation of contaminants occurring in the subsurface (Elsner et al., 2005). Although non-degradative dispersion processes do not fractionate, biodegradation often does, altering the isotopic signature of the residual contaminant pool (Meckenstock et al., 2004). This suggests that changes in isotopic values of residual chlorinated ethenes during degradation can be used to document degradation.

In order to fully utilize $\delta^{13} \mathrm{C}$ in field contaminant degradation studies, the isotopic enrichment factors $(\varepsilon)$ of a particular degradation mechanism need to be determined. The isotopic enrichment factor measures the extent of fractionation by employing the Rayleigh equation (Mariotti et al., 1981). This involves the analysis of the isotope ratios of the residual, not yet degraded, substrate and is useful because it relates differences in isotope ratios to changes in contaminant concentrations. 
Recently, stable carbon isotope ratios $\left(\delta^{13} \mathrm{C}\right)$ have been introduced as a tool to monitor biodegradation of chlorinated solvents. There are several laboratory studies that demonstrate carbon isotope fractionation of the remaining contaminant pool during anaerobic reductive dechlorination of tetrachloroethene (PCE) and TCE (Sherwood Lollar et al., 1999; Bloom et al., 2000; Slater et al., 2001; Cichocka et al., 2007). Additionally, studies have documented isotope fractionation from anaerobic processes occurring in situ (Hunkeler et al., 1999, 2004; Sherwood Lollar et al., 2001; Song et al., 2002; Vieth et al., 2003). Although many aquifers contain both aerobic and anaerobic regions, little research has examined the isotope fractionation measured during aerobic cometabolic degradation of TCE and c-DCE (Barth et al., 2002; Chu et al., 2004). In anaerobic systems reductive dechlorination of c-DCE results in about twofold greater fractionation than reductive dechlorination of TCE. Reported $\delta^{13} \mathrm{C}$ enrichment factors for anaerobic c-DCE degradation range from -12 to $-20.4 \%$ (Hunkeler et al., 1999, 2002; Bloom et al., 2000; Slater et al., 2001). TCE $\delta^{13} \mathrm{C}$ enrichment factors range from -2.5 to $-18.9 \%$ in anaerobic degradation (Hunkeler et al., 1999; Sherwood Lollar et al., 1999; Bloom et al., 2000; Slater et al., 2001; Cichocka et al., 2007).

Much of the interest in aerobic chlorinated ethene bioremediation has focused on toluene and methane oxygenases. Soluble methane monooxygenase (sMMO) and particulate methane monooxygenase (pMMO) are enzymes that cometabolically oxidize chlorinated ethenes. Chu et al. (2004) found that sMMO from Methylosinus trichosporium $\mathrm{OB} 3 \mathrm{~b}$ did not significantly fractionate c-DCE, but it did fractionate TCE with a $\delta^{13} \mathrm{C}$ enrichment factor of $-1.1 \%$. This $\delta^{13} \mathrm{C}$ enrichment factor is lower than the range reported for anaerobic TCE degradation (minimum of $-2.5 \% 0$ ). We are not aware of any reports of fractionation by pMMO. There are five known pathways for the oxidation of toluene which differ in the location of the initial oxidation (Worsey and Williams, 1975; Wackett and Gibson, 1988; Shields et al., 1989; Whited and Gibson, 1991; Olsen et al., 1994). Four of these five pathways cometabolically degrade TCE and other chlorinated ethenes (Hopkins and McCarty, 1995; Leahy et al., 1996; Ryoo et al., 2000; Shim et al., 2001). Only one study that we are aware of has investigated the ${ }^{13} \mathrm{C}$ isotopic fractionation of these pathways when degrading chlorinated ethenes (Barth et al., 2002). Their study of the toluene-2-monooxygenase (T2MO) of Burkholderia cepacia G4 indicated a greater fractionation of TCE $(\varepsilon=-18.2$ to $-20.7 \%$ o $)$ than has been seen in anaerobic reductive dechlorination of TCE (maximum of $-13.8 \%$ ).

The purpose of this study was to determine $\delta^{13} \mathrm{C}$ enrichment factors when degrading TCE and c-DCE for bacteria expressing particular toluene oxygenase pathways in order to extend the usefulness of stable carbon isotopic analysis to aerobic sites contaminated with TCE or c-DCE. The toluene oxygenase pathways studied and the bacterial strains containing them are: toluene dioxygenase (TDO), Pseudomonas putida F1 and P. fluorescens CFS215; toluene 3-monooxygenase (T3MO), Ralstonia pickettii PKO1; toluene 4-monooxygenase (T4MO), P. mendocina KR1. To our knowledge, our study is the first to investigate the carbon isotope fractionation by bacteria expressing these three toluene oxygenase pathways toward TCE and the first to investigate fractionation of c-DCE by bacteria containing toluene oxygenases.

\section{MATERIALS AND METHODS CHEMICALS}

All the media components except Noble agar (Difco Laboratories, Detroit, MI, USA) and $\left(\mathrm{NH}_{4}\right)_{2} \mathrm{SO}_{4}$ (Sigma Chemical Co., St. Louis, MO, USA) were obtained from Fisher (Fisher Scientific Co., Fair Lawn, NJ, USA). All other chemicals were obtained from Sigma. All these chemicals were reagent grade.

\section{CELL MAINTENANCE, GROWTH, AND PREPARATION}

Pseudomonas putida F1 and P. mendocina KR1 were provided by D. T. Gibson. P. fluorescens CFS215 and R. pickettii PKO1 were provided by R. H. Olsen.

The above strains were maintained in a liquid minimal medium containing $\left(\mathrm{NH}_{4}\right)_{2} \mathrm{SO}_{4}(0.1 \% \mathrm{w} / \mathrm{v})$, modified Hutner's mineral solution $(1 \% \mathrm{v} / \mathrm{v})$, and $40 \mathrm{mM}$ phosphate ( $\mathrm{pH} 7.3)$. Hutner's "concentrated base" mineral solution was modified to exclude nicotinic acid, thiamine, and biotin (Cohen-Bazire et al., 1957). Toluene was supplied $(100 \mu \mathrm{L} / 100 \mathrm{~mL}$ medium $)$ once a week and the cultures were incubated on a shaker at $30^{\circ} \mathrm{C}$.

For each strain there were four experimental treatments which were: live cells with c-DCE, killed cells with c-DCE, live cells with TCE, and killed cells with TCE. Five replicates for each straintreatment combination were performed. Due to logistical reasons, the replicates were performed sequentially. To allow for valid comparisons between strains, each replicate experiment consisted of all strain-treatment combinations.

Prior to each replicate for each strain $250 \mathrm{~mL}$ of minimal medium in $500 \mathrm{~mL}$ Erlenmeyer flasks was inoculated with $1 \mathrm{~mL}$ of the stock culture. Two hundred microliters of toluene was added and the flasks were sealed with screw caps. The cultures were incubated on a shaker at $30^{\circ} \mathrm{C}$ for $12 \mathrm{~h}$ (strains F1 and CFS215) or $48 \mathrm{~h}$ (strains KR1 and PKO1).

After incubation, nitrogen gas (Airgas, Radnor, PA, USA) was passed through a $0.1-\mu \mathrm{m}$ filter and bubbled through the cultures for $30 \mathrm{~min}$ to remove any remaining toluene. Half $(125 \mathrm{~mL})$ of each culture was then autoclaved to serve as killed controls. The optical density $\left(\mathrm{A}_{610}\right)$ of each culture was determined on a Spectronic Genesys 5 spectrophotometer (Thermo Scientific). As the optical density of the cultures were different from each other (between 0.5 and 1.5), the degradation rates were normalized to cell dry mass. Prior experiments had produced a standard curve for each strain correlating the optical density with the dry mass of cells per microliter of culture (data not shown).

For each replicate the four strains each had five $20 \mathrm{~mL}$ serum vials prepared for each treatment. Ten microliters of culture was placed in each vial and $70 \mu \mathrm{L}$ of a $1000-\mathrm{mg} / \mathrm{L}$ stock solution of c-DCE or TCE was added for a final concentration of $7 \mathrm{mg} / \mathrm{L}$ chlorinated ethene in each vial. Abiotic controls (six each for TCE and c-DCE) consisting of $10 \mathrm{~mL}$ of sterile medium and $70 \mu \mathrm{L}$ of the c-DCE or TCE stock were also prepared. Each vial contained $10 \mathrm{~mL}$ of headspace consisting of atmospheric air. All the vials were sealed with Mininert valves (VICI Precision Sampling, Inc., Houston, TX, USA). The vials were incubated inverted, shaking at $30^{\circ} \mathrm{C}$ in the dark.

At each time point $(0,12,24,48,72 \mathrm{~h})$ one vial from each strain-treatment combination was removed from the incubator and $100 \mu \mathrm{L}$ concentrated $\mathrm{HCl}$ was added to each vial with a syringe 
to kill the cells. Three abiotic controls of each chlorinated ethene were injected with the $\mathrm{HCl}$ at the start of the replicate and the remaining three for each chlorinated ethene were injected with $\mathrm{HCl}$ at the end of the replicate $(72 \mathrm{~h})$. The vials were stored at $4{ }^{\circ} \mathrm{C}$ in the dark until analyzed, typically within $48 \mathrm{~h}$.

\section{STABLE ISOTOPIC ANALYSIS}

Trichloroethene and c-DCE were extracted from each vial using a headspace equilibration technique (Slater et al., 1999). Sealed vials were incubated in a forced air drying oven at $60^{\circ} \mathrm{C}$ for at least $30 \mathrm{~min}$ prior to analysis. After equilibration, $1 \mathrm{~mL}$ of headspace was manually injected into a Thermo Trace GC using a 1-mL SGE gastight syringe. Samples were analyzed for $\delta^{13} \mathrm{C}$ on a ThermoFinnigan Trace GC interfaced with a Thermo-Finnigan DeltaPlus isotope ratio mass spectrometer. The GC was equipped with a DB624 capillary column. The following GC temperature program was used: $40^{\circ} \mathrm{C}$ for $4 \mathrm{~min}$, increase the temperature to $90^{\circ} \mathrm{C}$ at a rate of $15^{\circ} \mathrm{C} / \mathrm{min}$, hold at $90^{\circ} \mathrm{C}$ for $3 \mathrm{~min}$. The injector temperature was set at $250^{\circ} \mathrm{C}$ with a split ratio of $10: 1$ and the helium flow was $1.2 \mathrm{~mL} / \mathrm{min}$.

Concentration standards of c-DCE and TCE were made daily in sterilized medium in $20 \mathrm{~mL}$ serum vials and sealed with coated gray butyl septa and crimp-top aluminum caps. The peaks for c-DCE and TCE were identified based on retention time in the GC and concentrations were determined from a calibration curve generated from known standards using the GC peak areas. Carbon isotope ratios $\left(\delta^{13} \mathrm{C}\right)$ were calculated by comparing the $\delta^{13} \mathrm{C}$ value of c-DCE and TCE to a $\mathrm{CO}_{2}$ reference gas.

Low levels of leakage from the vials were observed for both c-DCE and TCE in abiotic controls (no-cell controls and killed cell controls). For each chlorinated ethene the leakage rates were essentially the same for all control vials. An average leakage rate was obtained from all the abiotic controls for each chlorinated ethene (0.004 $\mathrm{mg} \mathrm{c-DCE} / \mathrm{L} / \mathrm{h}$ and $0.003 \mathrm{mg} \mathrm{TCE} / \mathrm{L} / \mathrm{h})$ and was used to correct the concentrations of $\mathrm{c}-\mathrm{DCE}$ and TCE in the experimental vials. The corrections were based on the total time that the samples were incubated and stored before analysis. No significant fractionation was observed over time in the controls due to the leakage so the $\delta^{13} \mathrm{C}$ values were not corrected.

A Rayleigh model for closed systems was used to describe the changes in carbon isotopic ratios during biodegradation in terms of an isotopic enrichment factor $(\varepsilon)$ :

$\varepsilon \ln \left(f_{t}\right)=1000 \ln \left(\left(\delta^{13} \mathrm{C}_{t}+1000\right) /\left(\delta^{13} \mathrm{C}_{0}+1000\right)\right)$

where $f_{\mathrm{t}}$ is the fraction of substrate remaining at time $t$ and $\delta^{13} \mathrm{C}_{t}$ and $\delta^{13} \mathrm{C}_{0}$ are the isotopic ratios of the substrate at time $t$ and time 0 respectively. Assuming that the isotopic enrichment factor is constant, it can be determined by plotting the right side of the equation versus $\ln \left(f_{t}\right)$. The slope of the line obtained is the isotopic enrichment factor $(\varepsilon)$. The enrichment factors from the replicates for each strain-treatment combination were averaged and a SD calculated to produce the reported values.

Variation in the data is likely due to some concentration measurements that were close to the detection limit of the instrument and due to variability between replicates. The space where the experiments were incubated randomly varied in temperature over a range of $5^{\circ} \mathrm{C}$. Within a given replicate all four strains and all treatments experienced the same temperature variations, but for logistical reasons the replicates were run sequentially and thus each replicate experienced a different temperature regime.

\section{RESULTS}

All of the experimental vials exhibited little or no lag phase before the onset of degradation (Figure 1). For both contaminants, and for all four strains, degradation slowed to near zero after $24 \mathrm{~h}$. At this point the only experiment showing complete degradation was strain KR1 degrading c-DCE. For the three strains excluding KR1, c-DCE degradation left a little over a third of the starting concentration on average and for all four strains degrading TCE about two thirds of the initial concentration remained. Because the degradation began to slow by $24 \mathrm{~h}$, the degradation rates were calculated based on the first $12 \mathrm{~h}$. Strains F1, CFS215, and PKO1 degraded c-DCE at similar rates, whereas strain KR1, which expresses the toluene 4-monooxygenase, degraded c-DCE at a rate 5-9 times higher than the other strains (Table 1). All strains degraded c-DCE at a higher rate than TCE.

All four bacterial strains showed enrichment in ${ }^{13} \mathrm{C}$ over time in the remaining contaminant as both c-DCE and TCE were degraded (Figure 2). For strain KR1 the degradation of c-DCE occurred so quickly that there were too few data points to accurately determine the enrichment in ${ }^{13} \mathrm{C}$. From these data $\delta^{13} \mathrm{C}$ enrichment factors $(\varepsilon)$ were calculated using the Rayleigh equation (Table 2). Because the abiotic and killed cell controls showed no significant fractionation the Rayleigh equation was not applied to them (Figure 2). For the three strains excluding KR1 the $\delta^{13} \mathrm{C}$ enrichment factors for C-DCE degradation were not significantly different from each other (Table 2). All four strains had $\delta^{13} \mathrm{C}$ enrichment factors for the degradation of TCE that were much greater than seen for the degradation of c-DCE, and these $\delta^{13} \mathrm{C}$ enrichment factors were not significantly different from each other.

\section{DISCUSSION}

The effects of abiotic processes, such as volatilization and sorption to solids, on isotopic fractionation have been shown to be negligible for equilibrium partitioning of chlorinated ethenes (Poulson and Drever, 1999; Slater et al., 1999, 2000). Barth et al. (2002) demonstrated that fractionation due to sorption of TCE to biomass of killed B. cepacia G4 cells is less than $0.5 \%$ (the typical accuracy and reproducibility of continuous flow isotope analysis techniques). In line with these previous studies there was no significant fractionation during the experiment for TCE or c-DCE in the killed cell controls (Figure 2). This indicates that sorption to biomass or other bottle effects had no effect on the isotopic composition of the contaminants, and that the observed fractionation in the experimental vials results from enzymatic degradation and not from non-degradative processes.

As expected from theoretical predictions and previous observations (Semprini, 1997; Bradley, 2003), the more reduced molecule (c-DCE) was degraded (oxidized) faster than TCE for all the tested bacterial strains. Both TCE and c-DCE degradation rates were comparable to the low end of the range reported in previous studies being about $10 \%$ of the median degradation rates previously reported (Semprini, 1997; Arp et al., 2001). The halt in degradation 

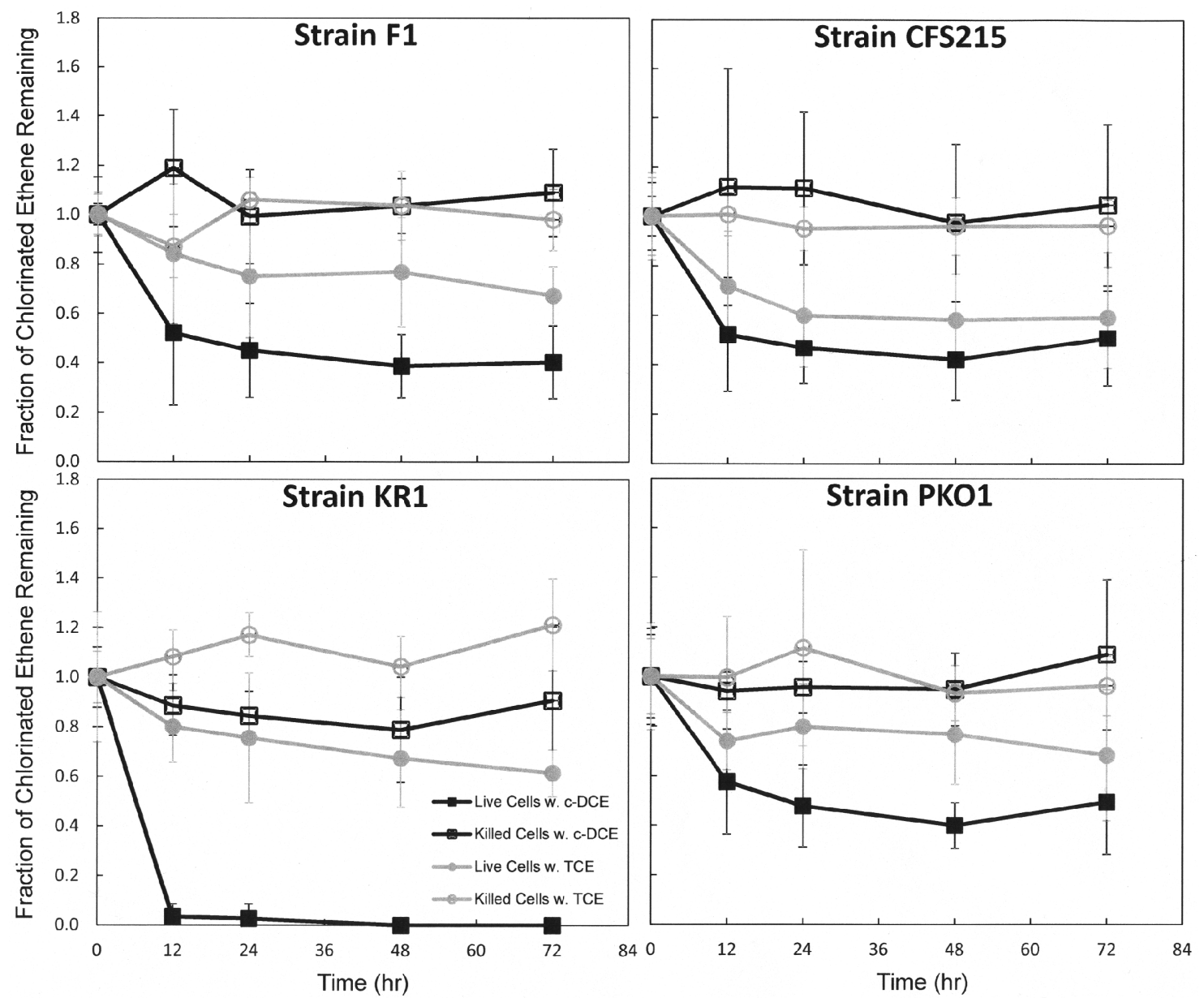

FIGURE 1 | Degradation curves of cis-1,2-dichloroethene (c-DCE) and trichloroethene (TCE) by four bacterial strains: Pseudomonas putida F1,

Table 1 | Degradation rates over the first $12 \mathrm{~h} \pm 1 \mathrm{SD}$ for cis-1,2-dichloroethene (c-DCE) and trichloroethene (TCE) by four bacterial strains: Pseudomonas putida F1, P fluorescens CFS215, P. mendocina KR1, and Ralstonia pickettii PKO1 containing three degradative pathways: toluene 2,3-dioxygenase (TDO), toluene 3-monooxygenase (T3MO), and toluene 4-monooxygenase (T4MO).

\begin{tabular}{llll}
\hline \multirow{2}{*}{ Strain } & Pathway & \multicolumn{2}{c}{$\mathbf{m g ~ C E} / \mathbf{m g}$ cell dry mass day } \\
\cline { 3 - 4 } & & c-DCE & TCE \\
\hline F1 & TDO & $0.067 \pm 0.021$ & $0.035 \pm 0.017$ \\
CFS215 & TDO & $0.038 \pm 0.015$ & $0.031 \pm 0.014$ \\
PKO1 & T3MO & $0.053 \pm 0.028$ & $0.034 \pm 0.017$ \\
KR1 & T4MO & $0.343 \pm 0.111$ & $0.098 \pm 0.068$
\end{tabular}

before completion is likely due to exhaustion of oxygen in the vials and the fact that no carbon source was present in the vials to provide reducing equivalents. Toxicity of the contaminants is also a factor to consider. TCE and c-DCE degradation have been shown to irreversibly inactivate monooxygenase enzymes as well as being
P. fluorescens CFS215, P. mendocina KR1, and Ralstonia pickettii PKO1. Each point is the average of five samples and the error bars indicate 1 SD. toxic to cells (van Hylckama Vlieg and Janssen, 2001) so it is reasonable to conclude that such effects may have occurred in the current study.

Trichloroethene degradation $\delta^{13} \mathrm{C}$ enrichment factors were not significantly different among the four strains tested. These factors all fell into the range of $-11.6 \pm 4.1$ to $-14.7 \pm 3.0 \%$. This range overlaps the high end of the range of values reported for anaerobic TCE degradation (Table 3). The other reported toluene oxygenase pathway from strain G4 had an even higher fractionation than was observed for the toluene oxygenases in this study. Although toluene oxygenases tend to exhibit higher fractionation for TCE degradation than anaerobic degradative enzymes, the two processes (except for T2MO) cannot be conclusively distinguished based solely on carbon stable isotope fractionation. All of the toluene oxygenases examined fractionate TCE much more strongly than sMMO, the only other reported fractionation for an aerobic TCE biodegradation pathway. Because these toluene oxygenases are all phylogenetically related and are thought to act by the same mechanism, it is not surprising that their enrichment factors are similar. Because the variation in our data was relatively high, it is possible that future refinement in the methods that results in 

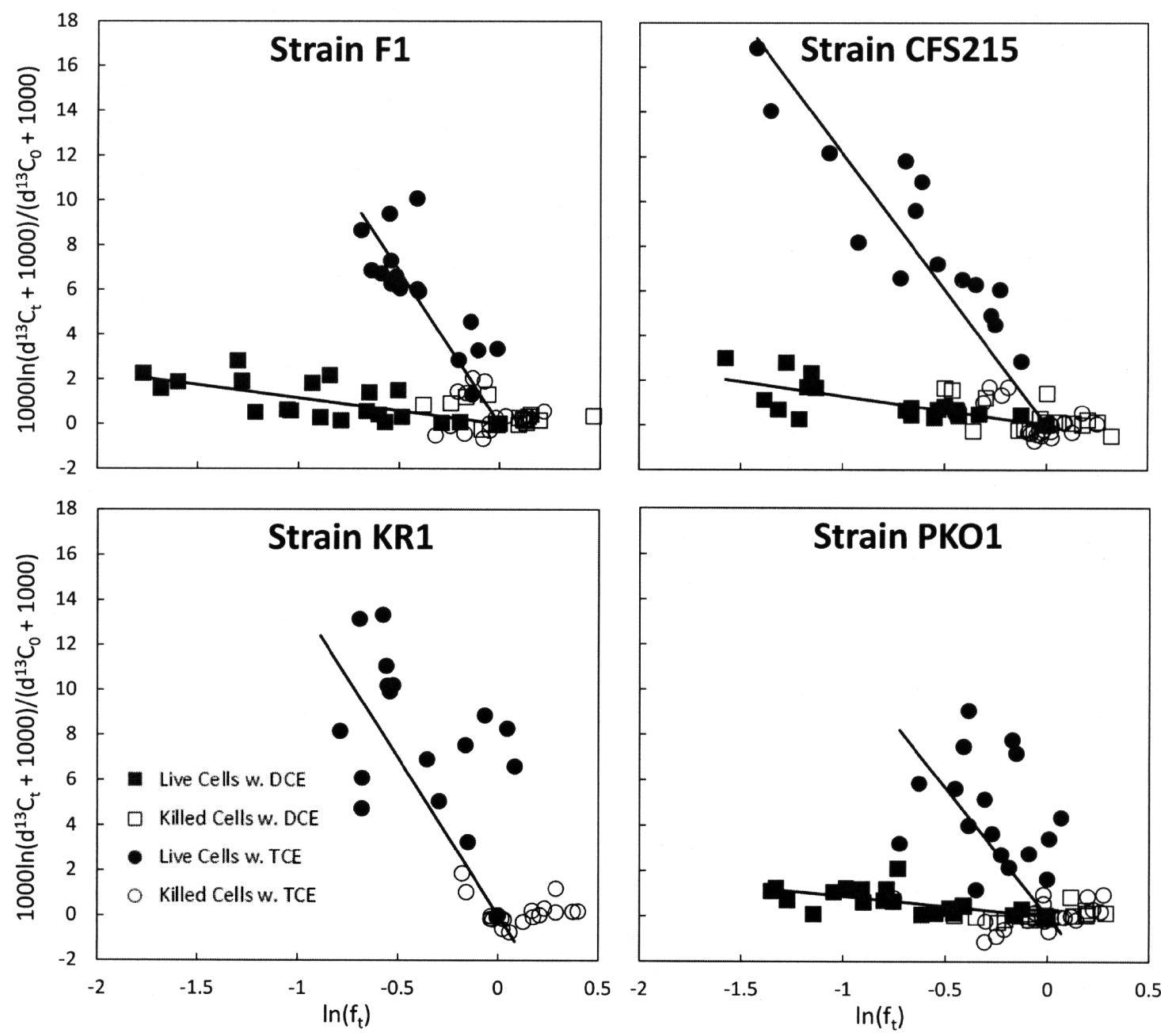

FIGURE 2 | Rayleigh plots of ${ }^{13} \mathrm{C}$ during degradation of $c i s-1,2$-dichloroethene (c-DCE) and trichloroethene (TCE) by four bacterial strains: Pseudomonas putida F1, P. fluorescens CFS215, P. mendocina KR1, and Ralstonia pickettii PKO1.

Table 2 | Enrichment factors $(\varepsilon)$ expressed in \%o \pm 1 SD for $\delta^{13} \mathrm{C}$ from degradation of cis-1,2-dichloroethene (c-DCE) and trichloroethene (TCE) by four bacterial strains: Pseudomonas putida F1, P. fluorescens CFS215, P. mendocina KR1, and Ralstonia pickettii PKO1 containing three degradative pathways: toluene 2,3-dioxygenase (TDO), toluene 3-monooxygenase (T3MO), and toluene 4-monooxygenase (T4MO).

\begin{tabular}{llll}
\hline Strain & Pathway & c-DCE & TCE \\
\hline F1 & TDO & $-1.10 \pm 0.77$ & $-13.82 \pm 1.55$ \\
CFS215 & TDO & $-1.23 \pm 0.45$ & $-14.70 \pm 3.02$ \\
PKO1 & T3MO & $-0.89 \pm 0.51$ & $-11.60 \pm 4.11$ \\
KR1 & T4MO & ND & $-14.40 \pm 6.44$
\end{tabular}

ND, not determined.

a lower variability could show small differences in the enrichment factors of different enzymes.

The three bacterial strains excluding KR1 did not significantly differ in fractionation during degradation of c-DCE, with $\delta^{13} \mathrm{C}$ enrichment factors falling in the range of $-0.9 \pm 0.5$ to $-1.2 \pm 0.5 \%$. The much lower fractionation seen in c-DCE degradation compared to TCE degradation could be linked to the much faster degradation of c-DCE than TCE. This faster degradation indicates that the enzyme transforms c-DCE more easily than TCE which means that the enzyme will be less affected by the different bond strengths in molecules of c-DCE containing different carbon isotopes than in TCE transformation. As is the case for TCE degradation, this fractionation is greater than seen during degradation by sMMO, the only oxygenase to be tested for carbon fractionation from degradation of c-DCE (Chu et al., 2004; Table 3). In contrast to the sMMO and toluene oxygenase data, anaerobic degradation of c-DCE shows a strong carbon isotope fractionation ranging from -12 to $-20.4 \%$ o (Hunkeler et al., 1999, 2002; Bloom et al., 2000; Slater et al., 2001). Since the aerobic and anaerobic degradation of c-DCE are different in their extent of fractionation, these data can be used to distinguish between the aerobic versus anaerobic degradation at a contaminated site as was demonstrated in a model wetland 
Table 3 | Enrichment factors $(\varepsilon)$ expressed in \%o for $\delta^{13} \mathrm{C}$ from degradation of cis-1,2-dichloroethene (c-DCE) and trichloroethene (TCE) by six degradative pathways as determined from this study and the literature: anaerobic reductive dechlorination, soluble methane monooxygenase (sMMO), toluene-2-monooxygenase (T2MO), toluene 3-monooxygenase (T3MO), toluene 4-monooxygenase (T4MO), and toluene 2,3-dioxygenase (TDO).

\begin{tabular}{lll}
\hline Pathway & C-DCE & TCE \\
\hline Anaerobic & -12.0 to $-25.5^{1}$ & -2.5 to $-18.9^{2}$ \\
SMMO & $-0.4 \pm 0.5^{3}$ & $-1.1 \pm 0.3^{3}$ \\
T2MO & & $-19.3 \pm 1.8$ \\
T3MO & $-0.89 \pm 0.51$ & $-11.60 \pm 4.11$ \\
T4MO & & $-14.40 \pm 6.44$ \\
TDO & $-1.17 \pm 0.60$ & $-14.31 \pm 2.38$
\end{tabular}

'Bloom et al. (2000), Slater et al. (2001), Hunkeler et al. (1999, 2002).

${ }^{2}$ Sherwood Lollar et al. (1999), Bloom et al. (2000), Slater et al. (2001), Cichocka et al. (2007).

${ }^{3}$ Chu et al. (2004).

The entries for each pathway indicate the mean and 1 SD of the data except for the anaerobic process where the range of values reported in the literature is given.

setting by Imfeld et al. (2008). However, the low fractionation observed in degradation by the aerobic pathways would make it difficult to distinguish between enzymatic biodegradation versus abiotic dispersion by dilution, etc. Fractionation from aerobic and anaerobic TCE degradation overlap each other and are only different at the extremes of their respective ranges (anaerobic $\delta^{13} \mathrm{C}$

\section{REFERENCES}

Abe, Y., Aravena, R., Zopfi, J., ShouakarStash, O., Cox, E., Roberts, J. D., and Hunkeler, D. (2009). Carbon and chlorine isotope fractionation during aerobic oxidation and reductive dechlorination of vinyl chloride and cis-1,2-dichloroethene. Environ. Sci. Technol. 43, 101-107.

Arp, D. J., Yeager, C. M., and Hyman, M. R. (2001). Molecular and cellular fundamentals of aerobic cometabolism of trichloroethylene. Biodegradation 12, 81-103.

Barth, J. A. C., Slater, G., Schüth, C., Bill, M., Downey, A., Larkin, M., and Kalin, R. M. (2002). Carbon isotope fractionation during aerobic biodegradation of trichloroethene by Burkholderia cepacia G4: a tool to map degradation mechanisms. Appl. Environ. Microbiol. 68, 1728-1734.

Bloom, Y., Aravena, R., Hunkeler, D., Edwards, E., and Frape, S. K. (2000). Carbon isotope fractionation during microbial dechlorination of trichloroethene, cis-1,2dichloroethene, and vinyl chloride: implications for assessment of natural attenuation. Environ. Sci. Technol. 34, 2768-2772.
Bradley, P. M. (2003). History and ecology of chloroethene biodegradation: a review. Biorem. J. 7, 81-109.

Chu, K.-H., Mahendra, S., Song, D. L., Conrad, M. E., and Alvarez-Cohen, L. (2004). Stable carbon isotope fractionation during aerobic biodegradation of chlorinated ethenes. Environ. Sci. Technol. 38, 3126-3130.

Cichocka, D., Siegert, M., Imfeld, G., Andert, J., Beck, K., Diekert, G., Richnow, H., and Nijenhuis, I. (2007). Factors controlling the carbon isotope fractionation of tetraand trichloroethene during reductive dechlorination by Sulfurospirillum ssp. and Desulfitobacterium sp. Strain PCE-S. FEMS Microbiol. Ecol. 62, 98-107.

Cohen-Bazire, G., Sistrom, W. R., and Stanier, R. Y. (1957). Kinetic studies of pigment synthesis by non-sulphur purple bacteria. J. Cell. Comp. Physiol. 49, 25-68.

Elsner, M., Zwank, L., Hunkeler, D., and Schwarzenbach, R. P. (2005). A new concept linking observable stable isotope fractionation to transformation pathways of organic pollutants. Environ. Sci. Technol. 39, 6896-6916.

enrichment factors below $-9.3 \%$ and aerobic $\delta^{13} \mathrm{C}$ enrichment factors above $-13.8 \%$ ). Therefore, carbon isotope fractionation has a somewhat limited utility in distinguishing between TCE degradation pathways, but it can be used to distinguish biodegradation of TCE from abiotic dispersion processes in both types of systems. Although carbon isotope fractionation alone may not be able to distinguish between various fates of c-DCE and TCE in the environment, it may prove valuable in conjunction with chlorine isotope fractionation to differentiate aerobic from anaerobic degradation as was demonstrated by Abe et al. (2009).

For bioremediation to be used at a contaminated site it is necessary to demonstrate that biodegradation is not only possible, but is actually happening. Stable isotopes are one of the few techniques available for demonstrating actual degradation. Fractionation during reductive dechlorination has been used as an indicator of biodegradation at TCE contaminated sites (Sherwood Lollar et al., 2001; Song et al., 2002; Vieth et al., 2003). Similarly, carbon isotope fractionation could be used as an indicator of biodegradation by toluene oxygenases at aerobic contaminated sites.

\section{ACKNOWLEDGMENTS}

We thank Breanne Espen and Kellie Kasper for their help in setting up these experiments. Funding for this project was provided by the Northern Arizona University Bioremediation Initiative (BIORIN) of the Environmental Research, Development, and Education for the New Economy (ERDENE) program. Funding was also provided by a Technology and Research Initiative Fund (TRIF) equipment award from Northern Arizona University.

Hopkins, G. D., and McCarty, P. L. (1995). Field evaluation of in situ aerobic cometabolism of trichloroethylene and three dichloroethylene isomers using phenol and toluene as the primary substrates. Environ. Sci. Technol. 29, 1628-1637.

Hunkeler, D., Aravena, R., and Butler, B. J. (1999). Monitoring microbial dechlorination of tetrachloroethene (PCE) in groundwater using compound-specific stable carbon isotope ratios: microcosm and field studies. Environ. Sci. Technol. 33, 2733-2738.

Hunkeler, D., Aravena, R., and Cox, E. (2002). Carbon isotopes as a tool to evaluate the origin and fate of vinyl chloride: laboratory experiments and modeling of isotope evolution. Environ. Sci. Technol. 36, 3378-3384.

Hunkeler, D., Chollet, N., Pittet, X. Aravena, R., Cherry, J. A., and Parker, B. L. (2004). Effect of source variability and transport processes on carbon isotope ratios of TCE and PCE in two sandy aquifers. J. Contam. Hydrol. 74, 265-282.
Imfeld, G., Aragones, C. E., Zeiger S., Von Eckstadt, C. V., Paschke, H., Trabitzsch, R., Weiss, H., and Richnow, H. H. (2008). Tracking in situ biodegradation of 1,2dichloroethenes in a model wetland. Environ. Sci. Technol. 42 7924-7930.

Leahy, J. G., Byrne, A. M., and Olsen, R. H. (1996). Comparison of factors influencing trichloroethylene degradation by toluene-oxidizing bacteria. Appl. Environ. Microbiol. 62, 825-833.

Magar, V. S., Fennell, D. E., Morse, J. J., Alleman, B. C., and Leeson, A. (eds). (2001). Anaerobic Degradation of Chlorinated Solvents; Sixth International In situ and On-Site Bioremediation Symposium. Columbus, $\mathrm{OH}$ : Battelle Press.

Mariotti, A., Germon, J. C., Hubert, P., Kaiser, P., Letolle, R., Tardieux A., and Tardieux, P. (1981). Experimental determination of nitrogen kinetic isotope fractionation: some principles; illustration for the denitrification and nitrification processes. Plant Soil 62, $413-430$. 
Meckenstock, R. U., Morasch, B., Griebler, C., and Richnow, H. H. (2004). Stable isotope fractionation analysis as a tool to monitor biodegradation in contaminated aquifers. J. Contam. Hydrol. 75, 215-255.

National Research Council (NRC). (2000). Natural Attenuation for Groundwater Remediation. Washington, DC: National Academy Press.

Olsen, R. H., Kukor, J. J., and Kaphammer, B. (1994). A novel toluene3-monooxygenase pathway cloned from Pseudomonas pickettii PKO1. J. Bacteriol. 176, 3749-3756.

Poulson, S. R., and Drever, J. I. (1999). Stable isotope $(\mathrm{C}, \mathrm{Cl}$, and $\mathrm{H})$ fractionation during vaporization of trichloroethylene. Environ. Sci. Technol. 33, 3689-3694.

Ryoo, D., Shim, H., Canada, K., Barbieri, P., and Wood, T. K. (2000). Aerobic degradation of tetrachloroethylene by toluene-o-xylene monooxygenase of Pseudomonas stutzeri OX1. Nat. Biotechnol. 18, 775-778.

Semprini, L. (1997). Strategies for the aerobic co-metabolism of chlorinated solvents. Curr. Opin. Biotechnol. 8, 296-308.

Sherwood Lollar, B., Slater, G. F., Ahad, J., Sleep, B., Spivack, J., Brennan, M., and MacKenzie, P. (1999). Contrasting carbon isotope fractionation during biodegradation of trichloroethylene and toluene: implications for intrinsic bioremediation. Org. Geochem. 30, 813-820.

Sherwood Lollar, B., Slater, G. F., Sleep, B., Witt, M., Klecka, G. M., Harkness, M., and Spivack, J. (2001). Stable carbon isotope evidence for intrinsic bioremediation of tetrachloroethene and trichloroethene at Area 6, Dover Air Force Base. Environ. Sci. Technol. 35, 261-269.

Shields, M. S., Montgomery, S. O., Chapman, P. J., Cuskey, S. M., and Pritchard, P. H. (1989). Novel pathway of toluene catabolism in the trichloroethylene-degrading bacterium G4. Appl. Environ. Microbiol. 55, 1624-1629.

Shim, H., Ryoo, D., Barbieri, P., and Wood, T. K. (2001). Aerobic degradation of mixtures of tetrachloroethylene, trichloroethylene, dichloroethylenes, and vinyl chloride by toluene-o-xylene monooxygenase of Pseudomonas stutzeri OX1. Appl. Microbiol. Biotechnol. 56, 265-269.

Slater, G. F., Ahad, J. M. E., Sherwood Lollar, B., Allen-King, R., and Sleep, B. (2000). Carbon isotope effects resulting from equilibrium sorption of dissolved VOCs. Anal. Chem. 72, 5669-5672.

Slater, G. F., Dempster, H. S., Sherwood Lollar, B., and Ahad, J. (1999). Headspace analysis: a new application for isotopic characterization of dissolved organic contaminants. Environ. Sci. Technol. 33, 190-194.
Slater, G. F., Sherwood Lollar, B., Sleep, B. E., and Edwards, E. A. (2001). Variability in carbon isotopic fractionation during biodegradation of chlorinated ethenes: implications for field applications. Environ. Sci. Technol. 35, 901-907.

Song, D. L., Conrad, M. E., Sorenson, K. S., and Alvarez-Cohen, L. (2002). Stable carbon isotope fractionation during enhanced in situ bioremediation of trichloroethene. Environ. Sci. Technol. 36, 2262-2268.

van Hylckama Vlieg, J. E. T., and Janssen, D. B. (2001). Formation and detoxification of reactive intermediates in the metabolism of chlorinated ethenes. J. Biotechnol. 85, 81-102.

Vieth, A., Muller, J., Strauch, G., Kastner, M., Gehre, M., Meckenstock, R. U., and Richnow, H. H. (2003). In-situ biodegradation of tetrachloroethene and trichloroethene in contaminated aquifers monitored by stable isotope fractionation. Isotopes Environ. Health Stud. 39, 113-124.

Wackett, L. P., and Gibson, D. T. (1988). Degradation of trichloroethylene by toluene dioxygenase in whole-cell studies with Pseudomonas putida F1. Appl. Environ. Microbiol. 54, 1703-1708.

Whited, G. M., and Gibson, D. T. (1991) Toluene-4-monooxygenase, a threecomponent enzyme system that catalyzes the oxidation of toluene to p-cresol in Pseudomonas mendocina KR1. J. Bacteriol. 173, 3010-3016.
Worsey, M. J., and Williams, P. A. (1975). Metabolism of toluene and xylenes by Pseudomonas putida (arvilla) mt2: evidence for a new function of the TOL plasmid. J. Bacteriol. 124, 7-13.

Conflict of Interest Statement: The authors declare that the research was conducted in the absence of any commercial or financial relationships that could be construed as a potential conflict of interest.

Received: 14 November 2011; accepted: 06 February 2012; published online: 20 February 2012.

Citation: Clingenpeel SR, Moan JL, McGrath DM, Hungate BA and Watwood ME (2012) Stable carbon isotope fractionation in chlorinated ethene degradation by bacteria expressing three toluene oxygenases. Front. Microbio. 3:63. doi: 10.3389/fmicb.2012.00063

This article was submitted to Frontiers in Microbiotechnology, Ecotoxicology and Bioremediation, a specialty of Frontiers in Microbiology.

Copyright (C) 2012 Clingenpeel, Moan, McGrath, Hungate and Watwood. This is an open-access article distributed under the terms of the Creative Commons Attribution Non Commercial License, which permits non-commercial use, distribution, and reproduction in other forums, provided the original authors and source are credited. 